\title{
Identifikasi Potentially Inappropriate Medications (PIMs) Berdasarkan Kriteria STOPP START pada Pasien Geriatri Rawat Inap di RS Advent Bandar Lampung
}

\author{
Siti Julaiha \\ Jurusan Farmasi Politeknik Kesehatan Tanjungkarang
}

\begin{abstract}
Abstrak
Identifikasi peresepan obat pada populasi geriatri sangat penting untuk terus dilakukan karena peresepan yang membahayakan pada populasi ini akan berasosiasi dengan peningkatan morbiditas, terjadinya kejadian yang tidak diinginkan terkait obat, dan mortalitas. Tujuan penelitian ini adalah untuk mengidentifikasi PIM (Potentially Inappropriate Medication) pada pasien geriatri rawat inap di RS Advent Bandar Lampung pada tahun 2016 berdasarkan Kriteria STOPP START. Jenis penelitian ini adalah deskriptif. Populasi dalam penelitian ini adalah seluruh rekam medik pasien geriatric yang berobat rawat inap di RS Advent Bandar Lampung tahun 2016 dengan jumlah sampel sebanyak 72 rekam medik. Uji statistic yang digunakan adalah uji Chi square. Identifikasi penggunaan PIM disesuaikan dengan criteria STOPP START. Hasil analisis univariat menunjukkan tiga jenis PIM terbanyak pada pengobatan pasien geritari di RS Advent Bandar Lampung adalah tidak digunakannya statin pada pasien yang memiliki riwayat penyakit jantung koroner dan cerebral vascular disease $(51,28 \%)$, adanya duplikasi kelas obat $(17,95 \%)$, dan penggunaan benzodiazepine pada pasien yang berisiko jatuh (11,43\%). Analisis bivariat menunjukkan tidak ada hubungan secara bermakna antara kejadian PIM dengan jenis kelamin, usia, jumlah obat yang diberikan, komorbid, dan lama rawat.
\end{abstract}

Kata Kunci : Geriatri, STOPP START

\section{Identification of Potentially Inappropriate Medications (PIMs) Using STOPP START Criteria in Hospitalized Geriatric Patients at Advent Hospital Bandar Lampung}

\begin{abstract}
The identification of drug prescribing in geriatric population is important to do because a harmful prescribing in this population will be associated with increased morbidity, the occurrence of adverse drug events, and mortality. The aims of this study were to identify PIM (Potentially Inappropriate Medication) in hospitalized geriatric patients at Advent Hospital Bandar Lampung period 2016 using The STOPP START Criteria. This research is a descriptive study using data from medical record. The population of this study were all medical records of hospitalized geriatric patients at Advent Hospital Bandar Lampung periode 2016 with a total sample of 72 medical records. The statistical test used Chi square test with significance of $95 \%$. The result of univariate analysis showed that three of the highest PIM of hospitalized geritaric patients at Advent Hospital Bandar Lampung were statin not used in patients with history of coronary heart disease and cerebral vascular disease $(51,28 \%)$, duplication of drug class $(17,95 \%)$, and benzodiazepine use in patients at risk of fall $(11.43 \%)$. Bivariate analysis showed no significant relationship between PIM events with sex, age, amount of drug given, comorbid, and length of stay.
\end{abstract}

Keywords : geriatric, STOPP START

Korespondensi : Siti Julaiha, Jurusan Farmasi Politeknik Kesehatan Tanjungkarang, Jl Soekarno Hatta No.1 Bandar Lampung, Mobile 085366248889 e-mail : 


\section{Pendahuluan}

Jumlah penduduk usia lanjut di Indonesia mencapai peringkat lima besar terbanyak di dunia, yakni 18,1 juta pada tahun 2010 dan akan meningkat dua kali lipat menjadi 36 juta pada tahun 2025. Angka harapan hidup penduduk Indonesia mencapai 67,8 tahun pada tahun 2000-2005 dan menjadi 73,6 tahun pada tahun 2020-2025.5 Proporsi usia lanjut meningkat 6\% pada tahun 1950-1990 dan menjadi 8\% saat ini. Proporsi tersebut diperkirakan naik menjadi $13 \%$ pada tahun 2025 dan menjadi 25\% pada tahun 2050. Pada tahun 2050 seperempat penduduk Indonesia merupakan penduduk usia lanjut, dibandingkan seperduabelas penduduk Indonesia saat ini. Isu penting peningkatan populasi usia lanjut adalah perlunya rencana strategis perawatan kesehatan usia lanjut untuk meningkatkan kapasitas fungsional dan kualitas hidup yang mengacu pada konsep baru proses menua/aging (Setiati, 2013).

Penyakit kronis yang diderita pasien usia lanjut dan beberapa kondisi medis mengakibatkan pasien harus menerima beberapa obat yang dikenal dengan polifarmasi. Kondisi farmakokinetika dan farmakodinamika pada pasien usia lanjut telah mengalami perubahan. Kurangnya perhatian terhadap perubahan ini berkontribusi terhadap penggunaan obat yang tidak tepat ( (Ubeda, Ferrandiz, Maicas, Gomez, Bonnet, \& Peris, 2012).

Identifikasi peresepan obat pada populasi geriatri sangat penting untuk terus dilakukan karena peresepan yang membahayakan pada populasi ini akan berasosiasi dengan peningkatan morbiditas, terjadinya kejadian yang tidak diinginkan terkait obat, dan mortalitas. Pemilihan obat pada populasi geriatri merupakan proses yang kompleks karena populasi geriatri sangat rentan terhadap peresepan obat yang tidak benar terkait dengan polifarmasi, adanya penyakit penyerta, perubahan kodisi fisiologis yang dapat mempengaruhi proses farmakokinetik dan sensitivitas farmakodinamik terhadap obatobatan tertentu.

Secara umum, terapi farmakologis pada populasi geriatri dapat dikatakan aman jika obat yang diberikan mempunyai evidence-based data tentang keamanannya dan efektif dari segi biaya. Sebaliknya, akan berbahaya jika tidak mempunyai data tersebut karena berisiko menimbulkan efek samping tidak diinginkan yang tinggi apabila dibandingkan dengan penggunaannya pada populasi non-geriatri dan tentunya tidak efektif dari segi biaya (O’Mahony D \& Gallagher PF, 2008).

Keamanan peresepan pada populasi geriatri dapat diIdentifikasi mulai dari tahap proses atau pada tahap outcome secara eksplisit dan implisit. Pengukuran secara implisit dilakukan berdasarkan pada penilaian klinisi tentang keamanan obat tersebut pada individu pasien. Pengukuran secara eksplisit dilakukan berdasarkan kriteria yang ada, termasuk penelitian yang sudah dipublikasi, rekomendasi dari para ahli, dan konsensus bersama. Kriteria STOPP START adalah salah satu kriteria yang banyak digunakan untuk mengIdentifikasi keamanan terapi farmakologi pada populasi geriatri secara eksplisit.

Penelitian tentang penggunaan obat yang berpotensi tidak tepat atau potentially inappropriate medication (PIM) pada populasi geriatri masih sangat jarang dilakukan di Indonesia. Kasus PIM yang terjadi pada pasien geriatri perlu mendapat perhatian khusus karena kasus PIM dapat meningkatkan risiko terjadinya reaksi obat tidak dikehendaki (ROTD).

Terkait belum pernah dilakukannya penelitian mengenai PIM terhadap pasien geriatri di Bagian/SMF Penyakit Dalam RS Advent Bandar Lampung, maka perlu dilakukan penelitian yang lebih komprehensif terkait permasalahan ini terhadap pasien geriatri yang dirawat di ruang rawat inap Bagian/SMF Penyakit Dalam RS Advent Bandar Lampung. Hasil dari penelitian ini diharapkan dapat memberikan gambaran yang bermanfaat untuk tenaga medis dan tenaga kesehatan lainnya dalam usaha mencegah dan mengurangi terjadinya PIM sehingga akan memberikan keamanan pengobatan pada pasien geriatri yang dirawat di Bagian/SMF ini. Hal ini dapat meningkatkan mutu pelayanan kesehatan dan mengurangi beban biaya perawatan akibat terjadinya PIM.

Tujuan penelitian ini adalah untuk mengidentifikasi PIM (Potentially Inappropriate Medication) pada pasien geriatri rawat inap di RS Advent Bandar Lampung berdasarkan kriteria STOPP START.

\section{Metode}

Jenis penelitian yang dilakukan bersifat deskriptif dengan variable penelitian adalah kejadian Potentially Inapropriate Medication (PIM) yaitu pengobatan yang berpotensi tidak 
tepat pada pasien geriatri rawat inap di $\mathrm{RS}$ Advent Bandar Lampung. Penelitian ini dilakukan di RS Advent Bandar Lampung pada bulan Juli hingga Agustus 2017.

Populasi penelitian adalah seluruh rekam medik pasien geriatric dengan usia $\geq 60$ tahun yang berobat rawat inap di RS Advent Bandar Lampung pada tahun 2016. Sampel yang diambil adalah minimal 72 rekam medik pasien geriatric terpilih yang mewakili seluruh populasi.

Jenis data dalam penelitian ini adalah data sekunder yang diperoleh dengan cara mengobservasi data rekam medik pasien geriatri rawat inap tahun 2016 di RS Advent Bandar Lampung. Data yang didapatkan meliputi usia, jenis kelamin, lama rawat, komorbid, dan jenis obat beserta jumlah obat yang diterima pasien.

Analisis data dilakukan secara univariat dan bivariat. Analisis univariat dilakukan untuk melihat distribusi frekuensi kejadian PIM pada pasien geriatri rawat inap di RS Advent Bandar Lampung. Identifikasi kejadian PIM dilakukan dengan cara membandingkan data pengobatan yang diperoleh dengan menggunakan kriteria STOPP START sebagai standar.

Analisis bivariat dilakukan untuk mengetahui apakah ada perbedaan kejadian PIM ditinjau dari factor usia, jenis kelamin, lama rawat, komorbid, dan jumlah obat dengan menggunakan uji chi square dengan tingkat kemaknaan $95 \%$.

\section{Hasil}

\section{Analisa Data Univariat}

Jumlah pasien geriatri yang dijadikan sampel pada penelitian ini sebanyak 72 orang, yang terdiri dari 40 pasien laki-laki dan 32 pasien perempuan. Tabel 1 menunjukkan data demografi sampel penelitian. Distribusi frekuensi sampel penelitian berdasarkan data demografi meliputi kelompok usia, jenis kelamin, jumlah obat yang diberikan, komorbid, dan lama rawat. Sebagian besar pasien geriatri berusia antara 60-74 tahun $(79,2 \%)$ dan hanya $20,8 \%$ yang berusia di atas 74 tahun.
Obat-obatan yang diterima oleh 72 pasien tersebut selama rawat inap paling sedikit 2 jenis dan paling banyak 13 jenis obat. Sebagian besar pasien geriatri mendapatkan obat dengan jumlah sebanyak 5 jenis atau lebih $(69,4 \%)$ selama dirawat. Pasien yang mendapatkan jumlah obat kurang dari 5 jenis sebanyak $30,6 \%$.

Pasien geriatri yang tidak disertai dengan komorbid sebanyak $51,4 \%$ dan sisanya $(48,6 \%)$ disertai dengan komorbid. Rentang lama rawat pasien geriatri di RS Advent Bandar Lampung berkisar antara 3-12 hari. Pasien yang dirawat selama $<7$ hari sebanyak 93,1\% dan hanya $6,9 \%$ pasien dirawat selama 7 hari atau lebih.

Tabel 1. Data Demografi Sampel Penelitian

\begin{tabular}{|c|c|c|}
\hline \multirow{2}{*}{ Demografi } & \multicolumn{2}{|c|}{ Jumlah } \\
\hline & $\mathbf{n}$ & $(\%)$ \\
\hline \multicolumn{3}{|l|}{ Jenis Kelamin : } \\
\hline 1. Laki-laki & 40 & 55,6 \\
\hline 2. Perempuan & 32 & 44,4 \\
\hline \multicolumn{3}{|l|}{ Usia : } \\
\hline 1. 60-74 tahun & 57 & 79,2 \\
\hline 2. $\quad \geq 75$ tahun & 15 & 20,8 \\
\hline \multicolumn{3}{|l|}{$\begin{array}{l}\text { Jumlah Obat yang diberikan } \\
\text { selama rawat Inap : }\end{array}$} \\
\hline $1 .<5$ & 22 & 30,6 \\
\hline 2. $\geq 5$ & 50 & 69,4 \\
\hline \multicolumn{3}{|l|}{ Komorbid : } \\
\hline 1. Tidak ada & 37 & 51,4 \\
\hline 2. Ada & 35 & 48,6 \\
\hline \multicolumn{3}{|l|}{ Lama Rawat (hari) } \\
\hline 1. $<7$ hari & 67 & 93,1 \\
\hline 2. $\geq 7$ hari & 5 & 6,9 \\
\hline TOTAL SAMPEL & 72 & 100 \\
\hline
\end{tabular}

Untuk mengetahui kejadian PIM pada pasien geriatri rawat inap di RS Advent Bandar Lampung, dilakukan identifikasi pengobatan pada pasien dengan menggunakan kriteria STOPP START.

Hasil penelitian pada tabel 2 menunjukkan bahwa jumlah pasien geriatric yang mengalami kejadian PIM selama rawat inap sebanyak 35 pasien $(48,6 \%)$. Jumlah total kejadian PIM yang ditemukan selama pengobatan sebanyak 39 PIM. 
Tabel 2. Jenis PIM berdasarkan criteria STOPP START pada Sampel Penelitian

\begin{tabular}{clccc}
\hline \multirow{2}{*}{ Kode } & \multicolumn{1}{c}{ PIM } & \multicolumn{2}{c}{ Jumlah } \\
\cline { 3 - 5 } & \multicolumn{1}{c}{ A } & 1 & 2,54 \\
\hline A11 & Aspirin dengan sejarah penyakit peptic ulcer & 1 & 2,54 \\
\hline D2 & $\begin{array}{l}\text { Pemilihan kortikosteroid sistemik daripada kortikosteroid } \\
\text { inhalasi untuk terapi pemeliharaan pada PPOK sedang-parah. }\end{array}$ & 1 & 2,54 \\
\hline G1 & Glibenklamide pada pasien DM tipe 2 & 4 & 10,26 \\
\hline H1 & Benzodiazepin pada pasien yang berisiko jatuh & 7 & 17,95 \\
\hline J & Duplikasi kelas obat & 2 & 5,13 \\
\hline S3 & $\begin{array}{l}\text { Start Antihipertensi pada pasien dengan peningkatan tekanan } \\
\text { darah sistolik > 160 mmHg }\end{array}$ & 3 & 7,69 \\
\hline S13 & $\begin{array}{l}\text { Start PPI pada pasien usia > 80 tahun yang tengah mendapatkan } \\
\text { terapi aspilet }\end{array}$ & 20 & 51,28 \\
\hline S14 & $\begin{array}{l}\text { Start Statin pada pasien yang memiliki riwayat penyakit jantung } \\
\text { koroner, Cerebral Vascular disease }\end{array}$ & 39 & 100 \\
\hline & \multicolumn{1}{c}{ TOTAL KEJADIAN } & & \\
\hline
\end{tabular}

\section{Analisa Data Bivariat}

Untuk mengetahui hubungan antara antara jenis kelamin, usia, jumlah obat, komorbid, dan lama rawat dengan kejadian PIM pada Pasien Geriatri Rawat Inap di RS Advent
Bandar Lampung dilakukan uji Chi square. Hasil penelitian pada tabel 3 menunjukkan bahwa tidak ada hubungan yang bermakna antara kejadian PIM dengan jenis kelamin, usia, jumlah obat yang diberikan, komorbid, dan lama rawat.

Tabel 3. Hubungan antara Jenis Kelamin, Usia, Jumlah Obat, Komorbid, dan Lama Rawat dengan Kejadian PIM pada Pasien Geriatri Rawat Inap di RS Advent Bandar Lampung

\begin{tabular}{|c|c|c|c|c|c|}
\hline \multirow[t]{2}{*}{ Variabel Penelitian } & \multicolumn{2}{|c|}{ Ada PIM } & \multicolumn{2}{|c|}{ Tidak Ada PIM } & \multirow[t]{2}{*}{$\mathbf{p}$} \\
\hline & $\mathrm{n}=35$ & $(\%)$ & $\mathbf{n}=\mathbf{3 7}$ & $(\%)$ & \\
\hline \multicolumn{6}{|l|}{ Jenis Kelamin : } \\
\hline 1. Laki-laki & 23 & 65,7 & 17 & 45,9 & 0,147 \\
\hline 2. Perempuan & 12 & 34,3 & 20 & 54,1 & \\
\hline \multicolumn{6}{|l|}{ Usia : } \\
\hline 1. 60-74 tahun & 27 & 77,1 & 30 & 81,1 & 0,904 \\
\hline 2. $\quad \geq 75$ tahun & 8 & 22,9 & 7 & 18,9 & \\
\hline \multicolumn{6}{|c|}{ Jumlah Obat yang diberikan selama rawat Inap : } \\
\hline 1. $<5$ & 11 & 31,4 & 11 & 29,7 & 1 \\
\hline 2. $\geq 5$ & 24 & 68,6 & 26 & 70,3 & \\
\hline \multicolumn{6}{|l|}{ Komorbid : } \\
\hline 1. Tidak ada & 17 & 48,6 & 20 & 54,1 & 0.819 \\
\hline 2. Ada & 18 & 51,4 & 17 & 45,9 & \\
\hline \multicolumn{6}{|l|}{ Lama Rawat (hari) } \\
\hline 1. $<7$ hari & 31 & 88,6 & 36 & 97,3 & 0,321 \\
\hline 2. $\geq 7$ hari & 4 & 11,4 & 1 & 2,7 & \\
\hline
\end{tabular}

\section{Pembahasan}

Kejadian PIM pada penelitian ini diidentifikasi dengan menggunakan kriteria STOPP START yang merupakan kriteria yang didasarkan pada kejadian klinis terkini dan pendapat consensus panel para ahli. Kriteria STOPP START mengandung daftar PIM yang sebaiknya dihindari atau dilakukan pada pasien usia lanjut (Shahezwan et al., 2012). Jumlah pasien geriatric yang mengalami PIM selama rawat inap adalah sebanyak 35 pasien $(48,6 \%)$. Jumlah total kejadian PIM yang ditemukan selama pengobatan berdasarkan table 5.2 adalah sebanyak 39 PIM.

PIM dengan jumlah terbanyak ditemukan pada PIM dengan kode S14 sebanyak 20 PIM $(51,28 \%)$ dimana pasien dengan penyakit 
kardiovaskuler tidak mendapatkan terapi obat golongan statin. Pada kejadian PIM ini, pasien seharusnya mendapatkan terapi obat golongan statin. Akan tetapi, selama pengobatan pasien tidak diberikan obat golongan statin. Sebagian besar pasien yang tidak mendapatkan terapi statin ini adalah pasien dengan riwayat stroke dan hiperkolesterolmia.

$$
\text { Panduan }
$$

STOPP

START

merekomendasikan untuk dilakukan terapi obat golongan statin pada pasien dengan riwayat koroner, serebral atau penyakit vaskular perifer yang status fungsionalnya masih mandiri dalam aktivitas sehari-hari dan harapan hidup > 5 tahun.

Wilmot et al (2014) menyatakan bahwa penggunaan statin dapat mengurangi cardiovaskuler events dan kematian. Hasi lpenelitian meta analisis menyebutkan bahwa penggunaan statin dapat mengurangi kejadian stroke sebesar 23,8 \%.. beberapa studi menyatakan bahwa penggunaan statin akan meningkatkan luaran status fungsional setelah mendapat serangan stroke.

Penggunaan statin sebagai pretreatment mempunyai hubungan yang bermakna dengan peningkatan luaran status fungsional ketika pasien keluar dari rumah sakit (Yoon dkk, 2004: Reeves dkk, 2008). Hal ini mendukung penggunaan statin dengan segera sebagai terapi pada pasien - pasien setelah stroke dengan ratarata lama masa rawatan 5 hari (Yoon et al, 2004). Ada juga penelitian dari beberapa sumber menyebutkan bahwa pasien dengan angka kolesterol tinggi di dalam darahnya ternyata memiliki resiko kematian lebih rendah serta memiliki luaran status fungsional yang lebih baik dibanding pasien dengan angka kolesterol normal. Hal ini menjadi jelas bahwa fenomena ini adalah hasil efek pleotropik darigolongan statin selain efeknya dalam menurunkan angka kolesterol (Dicker et al., 1997).

Beberapa studi menyatakan bahwa penggunaan statin akan meningkatkan luaran status fungsional setelah mendapat serangan stroke. Penggunaan statin dengan segera sebagai penurun kadar lipid dapat meningkatkan luaran status fungsional dan mengurangi resiko terjadinya stroke (Moonis et al., 2005). Selain efek penurun kolesterol, ternyata terdapat efek statin yang lain, dimana statin juga memiliki efek immune modulatory yang dianggap dapat meningkatkan luaran status fungsional setelah stroke iskemik akut (Yoon dkk., 2004). Mengkonsumsi atorvastatin 1 hari setelah serangan stroke iskemik ternyata dapat meningkatkan luaran status fungsional pada hari ke-14 karena dapat mempengaruhi angiogenesis, neurogenesis dan sinaptogenesis dengan menginduksi peningkatan faktor endotel pembuluh darah (Moonis dkk., 2005).

Jumlah pasien stroke iskemik berulang yang menggunakan statin lebih banyak memberikan luaran status fungsional baik sedangkan pasien yang tidak mendapat terapi statin cenderung memberikan luaran status fungsional buruk. Terdapat hubungan antara pemberian statin pada pasien stroke iskemik berulang terhadap luaran status fungsional yang baik, dengan nilai kebermaknaan adalah 0,022 (Alexanderet al, 2016).

Frekuensi PIM terbanyak ke-2 pada total sampel penelitian adalah duplikasi kelas obat sebanyak 7 PIM $(17,95 \%)$ yang terdiri dari duplikasi 2 NSAID sebanyak 6 PIM dan duplikasi 2 benzodiazepine sebanyak 1 PIM. NSAID yang diberikan meliputi Ka diklofenak dan ketorolac, ibuprofen dan eterocoxib, paracetamol dan antalgin, aspilet dan asam mefenamat. Benzodiazepine yang diberikan meliputi diazepam dan klordiazepoxide.

Penggunaan duplikasi NSAID kurang efisien karena obat bekerja dengan mekanisme yang sama dan dapat meningkatkan risiko efek sampingnya yaitu perdarahan lambung. Puspitasari (2013) dalam penelitiannya menyebutkan bahwa alasan penggunaan duplikasi NSAID adalah karena pasien sudah dalam kondisi nyeri yang tidak tertangani hanya dengan satu NSAID saja. Kombinasi NSAID diberikan dalam dosis terapi yang lebih rendah dengan tujuan untuk mencegah peningkatan efek samping obat.

Pemilihan pengobatan untuk mengatasi nyeri pada pasien harus dievaluasi secara ketat dan berdasarkan pada acuan seperti Three steps ladder dari WHO (Shahezwan et al., 2012). Pengobatan nyeri ringan sedang berdasarkan Three steps ladder dimulai dengan menggunakan obat golongan nonopioid dan peningkatan dosis jika dibutuhkan sampai dosis maksimal yang direkomendasikan.pengobatan untuk nyeri sedang parah atau jika nonopioid tidak cukup mengobati nyeri dapat ditambahkan opioid untuk nyeri sedang seperti hidrokodon yang dikombinasikan dengan paracetamol. Pengobatan pada nyeri yang parah dapat menggunakan golongan opioid untuk nyeri sedang parah seperti morfin dan oksikodon beserta terapi adjuvant jika dibutuhkan.

Penggunaan duplikasi benzodiazepine pada pasien geriatric dikaitkan dengan reaksi obat tidak dikehendaki pada pasien geriatric. 
Benzodiazepine merupakan obat yang sering diresepkan pada pasien geriatric sebagai antianxietas. Suatu penelitian menyebutkan bahwa sebagian besar pasien geriatric yang mendapatkan terapi benzodiazepine mengalami efek samping terkait benzodiazepine. Hal ini dikaitkan dengan kondisi farmakokinetika dan farmakodinamika pada pasien geriatric. Rekasi obat tidak dikehendaki yang signifikan terjadi antara lain risiko jatuh, gangguan kognitif, sedasi, dan gangguan ketika berkendaraan. Hal ini dikaitkan dengan waktu paruh benzodiazepine yang panjang (Madhusoodanan, 2004)

Frekuensi PIM terbanyak ke-3 pada sampel penelitian adalah penggunaan benzodiazepine pada pasien yang berisiko jatuh. Jumlah penggunaan benzodiazepine sebanyak 4 PIM (10,26\%). Dari catatan rekam medik disebutkan bahwa pasien yang menerima benzodiazepine ini memiliki risiko jatuh sedang-tinggi. Benzodiazepine yang digunakan meliputi diazepam dan alprazolam.

Benzodiazepine dianggap tidak tepat pada pasien geriatric karena diikuti dengan efek sedasinya dan adanya risiko membuat jatuh serta mengurangi kemampuan sensori pasien geriatric (Shahezwan et al., 2012). Penelitian di Taiwan menunjukkan bahwa penggunaan benzodiazepine secara signifikan meningkatkan risiko jatuh dan trauma akibat jatuh khususnya fraktur tulang (Chen-Liang-Liu et al., 2011).

Peresepan benzodiazepine pada pasien geriatric masih umum dan prevalensi tinggi meskipun banyak penelitian yang melibatkan penggunaan benzodiazepine menunjukkan efek merugikan pada pasien geriatric. Larangan benzodiazepine pada pasien geriatric tidak perlu tetai penggunaannya harus dibatasi sebisa mungkin atau digantikan dengan terapi obat golongan lain jika memungkinkan. Benzodiazepine seperti laprazolam dan tanpa metabolic aktif dapat dijadikan pilihan jika perlu diresepkan (Shahezwan et al., 2012).

Hasil penelitian Puspitasari (2013) menunjukkan bahwa penggunaan benzodiazepine memiliki prevalensi paling tinggi. Benzodiazepine digunakan dengan alasan pasien membutuhkan dan penggunaannnya hanya dengan menggunakan dosis terapi yang kecil untuk meminimalisir efek samping yang mungkin terjadi.

Frekuensi PIM terbanyak ke-4 adalah tidak digunakannya PPI pada pasien usia $>80$ tahun yang tengah mendapatkan terapi aspirin sebanyak 3 PIM (7,69\%). Pasien yang mendapatkan terapi aspirin dalam penelitian ini adalah pasien dengan diagnosa stroke non hemoragic. Selain itu, dari hasil penelitian juga ditemukan satu $(2,54 \%)$ kejadian PIM di mana pasien mendapatkan terapi aspirin padahal pasien memiliki riwayat peptic ulcer.

Aspirin direkomendasikan untuk diberikan pada pasien dengan riwayat stroke, baik stroke hemoragic maupun non hemoragic. Penggunaan aspirin pada pasien stroke terkait dengan efek antiplateletnya. Antiplatelet merupakan obat yang digunakan sebagai pencegahan sekunder terhadap kejadian stroke karena terapi dengan obat antiplatelet ini memberikan keuntungan lebih besar dibandingkan dengan risikonya. Selain itu aspirin merupakan obat denga harga yang cukup murah. Dari hasil suatu penelitian didapatkan bahwa terapi aspirin dengan dosis $100 \mathrm{mg}$ pada pasien stroke dapat mencegah keparahan stroke (Uchiyama et al., 2016).

Dalam penggunaannya, aspirin memiliki efek samping terkait gastritis pada lambung. Aspirin merupakan obat golongan NSAID dengan mekanisme kerja menghambat kerja enzim COX-1 yang berperan untuk memetabolisme asam arakidonat menjadi prostaglandin. Prostaglandin merupakan precursor yang berfungsi sebagai gastroprotektor pada lambung. Dengan dihambatnya pembentukan prostaglandin maka akan berkurang jumlah prostaglandin sehingga dinding lambung dapat mengalami iritasi.

Obat golongan Proton Pump Inhibitor (PPI) harus diberikan ketika pasien geriatri dengan penyakit kardiovaskular mendapatkan terapi antiplatelet. Suatu penelitian menunjukkan bahwa sebagian besar pasien dengan penyakit kardiovaskuler mendapatkan terapi aspirin sebagai antiplatelet. Hasil penelitian ini menunjukkan bahwa besarnya annual risk untuk kejadian perdarahan selama penggunaan aspirin pada pasien usia 70 tahun adalah $3,4 \%$. Nilai annual risk ini meningkat sebesar $4,1 \%$ pada pasien dengan usia di atas 85 tahun. Obat golongan PPI direkomendasikan untuk diberikan kepada pasien geriatric dengan tujuan untuk mencegah kejadian perdarahan lambung (Elia, 2017; Mayor, 2017).

Frekuensi PIM terbanyak ke-5 adalah tidak diberikannya obat antihipertensi pada pasien dengan peningkatan tekanan darah sistolik > $160 \mathrm{mmHg}$ dengan jumlah kejadian sebanyak 2 PIM $(5,13 \%)$. Tekanan darah pasien mengalami kenaikan selama pasien dirawat (120/80 s.d 170/80 mmHg). Di catatan pengobatan tidak terdapat obat antihipertensi. Padahal peningkatan tekanan darah setelah 
beberapa kali pengukuran dapat diindikasikan bahwa pasien menderita hipertensi sehingga harus dipertimbangkan pemberian obat antihipertensi.

Hipertensi merupakan penyakit umum yang diderita oleh pasien geriatri di sebagian besar Negara. Hipertensi merupakan factor risiko bagi sebagian besar penyakit kardiovaskular. Banyak penelitian klinis menunjukkan bahwa terjadi pengurangan secara signifikan terhadap kejadian infark myocardial dan stroke ketika pasien diberikan terapi antihipertensi. Hipertensi pada pasien geriatric harus ditangani segera karena beberapa alasan, antara lain pasien geriatri yang menderita hipertensi berisiko untuk mengalami kejadian stroke, tekanan darah sistolik cenderung tinggi, dan terdapat komorbid yang menyertai. Penanganan penyakit hipertensi memberikan beberapa benefit antara lain : penurunan kejadian dementia sebesar 50\%, menekan progresivitas hipertensi sebesar 94\%, penurunan angka rawat pasien sebesar $42 \%$, dan penurunan biaya berobat sebesar $35 \%$ (Elliot \& Black, 2002). Penelitian lain menyebutkan bahwa penanganan hipertensi pada pasien geriatri dengan usia 80 tahun ke atas dapat menurunkan angka kematian sebesar $21 \%$ dan mengurangi angka kejadi stroke sebesar 30\% (Beckett et al, 2008). Hal ini menunjukkan betapa pentingnya penanganan hipertensi pada pasien geriatri.

Pada penelitian ini juga ditemukan kejadian 1 PIM $(2,86 \%)$ terkait dengan pemilihan kortikosteroid sistemik daripada kortikosteroid inhalasi untuk terapi pemeliharaan pada pasien geriatri yang menderita penyakit paru obstruktif kronik (PPOK). Dalam terapinya pasien diberikan metilprednisolon tab $4 \mathrm{mg}$. Penggunaan kortikosteroid sistemik dapat meneybabkan paparan yang tidak perlu untuk efek samping jangka panjang dari kortikosteroid sehingga penggunaannya dibatasi untuk pasien geriati. Efek samping yang dikhawatirkan terjadi yaitu pada system kardiovaskular (hipertensi, aritmia, bradikardi, edema), system saraf pusat (depresi, ketidakstabilan emosi, insomnia, sakit kepala), system pencernaan (mual, peptic ulcer, perdarahan pada lambung, pancreatitis, ) dan neuromuscular (osteoporosis, neuropati, myopati) (American Pharmacist Association, 2010).

Hasil analisis bivariat dengan uji chi square menunjukkan bahwa tidak ada hubungan secara bermakna anatar kejadian PIM dengan jenis kelamin, usia, jumlah obat yang diberikan, komorbid, dan lama rawat. Hal ini berbeda dengan hasil penelitian yang dilakukan oleh Puspitasari pada tahun 2013 yang menyatakan bahwa terdapat hubungan secara bermakna antara kejadian PIM dengan jumlah obat $(\mathrm{p}=0,015)$ dan lama rawat pasien $(\mathrm{p}=0,01)$. Demikian pula dengan penelitian yang dilakukan oleh Syuaib et al pada tahun 2012 yang menyatakan bahwa terdapat hubungan yang bermakna pada kejadian PIM ditinjau dari jumlah obat $(\mathrm{p}=0,01)$ yang diberikan. Perbedaan hasil penelitian ini dengan penelitian sebelumnya dimungkinkan karena perbedaan jumlah obat yang ditinjau dan sedikitnya jumlah sampel yang digunakan.

Keterbatasan dalam penelitian ini adalah Pengambilan data hanya berdasarkan data yang terdapat pada rekam medik sehingga Drug related Problem (DRP) yang mungkin terjadi disebabkan oleh PIM tidak dapat dievaluasi secara keseluruhan karena informasi rekam medis yang kurang (untuk data retrospektif) dan peneliti tidak terlibat langsung sampai melihat dan memantau kondisi klinis pasien.

Simpulan hasil penelitian ini adalah tiga jenis PIM terbanyak pada pengobatan pasien geritari di RS Advent Bandar Lampung adalah tidak digunakannya statin pada pasien yang memiliki riwayat penyakit jantung koroner dan cerebral vascular disease $(51,28 \%)$, adanya duplikasi kelas obat $(17,95 \%)$, dan penggunaan benzodiazepine pada pasien yang berisiko jatuh $(11,43 \%)$. Tidak terdapat hubungan secara bermakna antara kejadian PIM dengan jenis kelamin, usia, jumlah obat yang diberikan, komorbid, dan lama rawat. Berdasarkan simpulan tersebut, maka disarankan untuk dilakukan penelitian selanjutnya di Rumah Sakit dengan jumlah sampel yang lebih besar dan masalah medis lebih kompleks. Untuk Rumah Sakit disarankan agar mempertimbangkan kriteria STOPP START dalam pengobatan pada pasien geriatri sebagai alat pembelajaran dan evaluasi bagi dokter dan apoteker untuk mencegah PIM pada pasien geriatri.

\section{Ucapan terima kasih}

Penulis mengucapkan terima kasih kepada direktur RS Advent Bandar Lampung dan jajarannya yang telah memberikan ijin penelitian dan membantu dalam pengambilan sampel penelitian. 


\section{Daftar Pustaka}

1. Alexxander, Nugroho, Agung Endro., Pinzon Rezaldi T., (2016). peranan obat golongan statin terhadap luaran status fungsional pasien stroke iskemik berulang di rumah sakit. Jurnal Manajemen dan Pelayanan Farmasi : 1-12

2. American Pharmacist Assotiation. (2010). Geriatric Dosage Handbook $17^{\text {th }}$ edition. USA : Lexicomp

3. Beckett NS, Peters R, Fletcher AE, et al. for the HYVET Study Group. Treatment of hypertension in patients 80 years of age or older. N Engl J Med. 2008;359:971-974.

4. Chien-Liang Liu, Li-Ning Peng, Yi-Tsu Chen, Ming-Hsien Lin, Li-Kuo Liu, \&Liang-Kung Chen. (2012). Potentially Inappropriate Prescribing (IP) for Elderly Medical Inpatients in Taiwan : A hospitalbased study. Archives of Gerontology and Geriatrics, 148-151

5. Dicker, A.G., Weir, C.J., Lees, K.R. (1997). Influence of cholesterol on survival after stroke: retrospective study', $B M J$, 314:1584-1588.

6. Elia, Joe,. (2017). In the Elderly, Add PPIs to Aspirin for Secondary Prevention. NEJM Journal Watch.

7. Elliott, William J \& Black, Henry R. (2002). Treatment of Hypertension in the Elderly. "http://www.medscape.com/viewpublicatio n/409" The American Journal of Geriatric Cardiology

8. Gallagher, P., \& O'Mahony, D. (2008). STOPP (Screening Tool of Older Person's Potentially Inappropriate Prescriptions) : Application to Acutely ill Elderly Patients and Comparison with Beers' Criteria. Age and Ageing Oxford Journals , 673-678.

9. Mayor, Susan. (2017). Older patients should take PPIs to cut risk of bleed from aspirin, study says. London : BMJ TResearch News

10. Madhusoodanan S \& Bogunovic OJ., (2004). Safety of Benzodiazepines in The Geriatric Polpulation.New York : Pubmed
11. Moonis, M., Kane, K., Schwiderski, U., Sandage, B.W., Fisher, M.. (2005), 'HMGCoA Reductase Inhibitors Improve Acute Ischemic Stroke Outcome', Stroke, 36:1298-1300.

12. Primedje, D. P., Bojita, M. T., \& Popa, A. (2016). Potentially Inappropriate Medications in Elderly Ambulatory and Institutionalized Patients : An Observational Study . BMC Pharmacology and Toxicology , 1-10.

13. Puspitasari, Rara Merinda. (2013). Uji Efektivitas "screening Tool For Older Peoples' Prescription" terhadap pengobatan yang berpotensi tidak tepat pada pasien geriatri di RSUD Kota Depok. Depok : Universitas Indonesia

14. Reeves, M..J, Gargano, J.W., Luo, Z., Mullard, A.J., Jacobs, B.S., Majid, A., dkk. (2008). National Acute Stroke Registry Michigan Prototype Investigators: Effect of pretreatment with statins on ischemic stroke outcomes. Stroke, 39:1779-85.

15. Shahezwan, M., Wahab, A., Nyforthansen, K., \& Kowalski S.R., (2012). Inappropriate Prescribing in Hospital Australian elderly as determination by STOPP Criteria. Int J Clin Pharm, 34. 855862

16. Setiati, S. (2013). Geriatric Medicine, Sarkopenia, Frailty dan Kualitas Hidup Pasien Usia Lanjut Tantangan Masa Depan Pendidikan, Penelitian dan Pelayanan Kedokteran di Indonesia. Geriatric Medicine, Sarkopenia, Frailty Journal , 240-250.

17. Ubeda, A., Ferrandiz, M. L., Maicas, N., Gomez, C., Bonnet, M., \& Peris, J. E. (2012). Potentially inappropriate prescribing in institutionalised older patients in Spain:the STOPP-START criteria compared with. Pharmacy Practice , 83-93.

18. Uchiyama., Sinichiro et al. (2016). Aspirin for Stroke Prevention in Elderly Patients With Vascular Risk Factors Japanese Primary Prevention Project. Ahajournals, 1605-1611. 
19. Yoon, S.S., Dambrosia, J., Chalela, J., Ezzeddine, M., Warach, S., Haymore, J. (2004). 'Rising statin use and effect on ischemic stroke outcome', BMC Medicine, 2:4-7.

20. Wilmot, Kobina., Khan, Abdullah., Krishnan, Sandeep., Eapen, Danny J., \& Sperling, Laurence. (2015). Statins in the Elderly : A Patient-Focused Approach. Clin. Cardiol. 38, 1, 56-61. 